\title{
Discussions on the University English Teaching Influenced by Traditional Education Mode and the Multimedia Education Mode
}

\author{
Kun Liu \\ Foreign Language Department, Changchun University of Science and Technology, Changchun, 130022, China
}

\begin{abstract}
The purpose of this paper is to analyze the merits and shortcoming of the traditional education mode and the multimedia education mode. How to supplement the two patterns is the priority which we should think over and explore during teaching. The suggestion that we should improve university English education mode based on making up for one's deficiency by learning from others' strong points for promoting the present university English teaching to adapt our foreign language teaching movement will be figured out in the paper.
\end{abstract}

Index Terms - traditional education mode, multimedia education mode, leading role

\section{INTRODUCTION}

The college English has been popularized as a compulsory subject in all universities completely in our country for decades. Our historical culture has play an important role in the world and the international arena proves more demands for English application as a communicative medium, thus the public's expectations for English education will increase with them. Yet it is not hard for us to figure out the traditional English teaching mode has been weak in current environment. How to get rid of the drawbacks of traditional English teaching for adapting to the development of the times, which has become the breaking point for reforming current college English teaching mode. Simultaneously, the rapid moving of computer network provides a new platform for English expansion education and a great chance for reforming the teaching mode as well as some new methods. So how to remove the weakness and absorb the spirit from the traditional teaching mode, and how to explore the new English teaching mode which is connected with international development with the computer network----the front scientific tool, thus the whole application on English of college students will be improved, which is the serious problem.

\section{Methodology}

\section{A. Traditional Teaching Mode}

Teaching mode refers to a stable structure which performs the teaching activity in some environment under the guidance of certain teaching ideas, teaching theory and learning conception. The factors composing teaching activities include teachers, students, text books and media, but in the traditional teaching mode, the phenomenon that emphasized the influence of teachers and ignored the need of students is common. The standard for judging teaching process is focus on whether the teachers prepared their teaching plan seriously and detailed, whether the classes are vivid and rich, whether the teaching procedure is ordered and obviously. The standard for judging teaching results is focus on quantitative assessment. The traditional college English teaching method based on the previous points refers to the speaking of teachers and listening of students, that is, teachers who stand on the podium with a box of chalks and a blackboard are the main-body in class, students who sit at their desks with a pen and a notebook are the sub-body. Therefore, the features of traditional teaching methods can be divided into five parts, one is rigid in the teaching environment and study environment as well as in the teaching procedure; the second is circling the teachers in the classes, less chances left for students to practicing listening and speaking, the third is emphasizing the grammatical knowledge and reading comprehension and ignoring listening and speaking; the forth is teacher-centered flaw, that is teachers are good at teaching in categories that forms by splitting the grammar and vocabulary into fragments, which deviated from the essence of language application and overlooked the practicality; the last, it is lack of disciplines in assigning the independent learning outside the classroom. All of above resulted in the losing interests in studying. In 2007 July, the Ministry of Education promulgated the "Requirements for College English Curriculum", which pointed out obviously that university should improve the single teaching mode which centered the teachers only based on the fully application of modern information techniques to adapt to a new English teaching mode based on the computers and students-centered class, so the education could make its way to personalizing and independence direction.

But the traditional teaching methods are not meaningless, in the natural learning environment that is poor in providing a broad space for students; teachers-centered classroom is the vital trace for our English learning. With the 
teaching experience gathered in the years, teachers could grasp the actual level of students's learning generally in the classes, and they could motorize individuals respectively in some scale, adjust the exact contents during the teaching process flexibly without being limited in the teaching plan fixedly, also the teachers can regulate the class atmosphere and the teaching methods at any time in the communication, as well as they can have their free space to display the knowledge and explain the text with their experienced skills and knowledge. When necessary, when the classes are tedious or boring, they can change the teaching procedure and teaching content by adapting to a relative flexible manner to get to the positive class effect, generally they could adjust the practice period for helping students master the knowledge learned just now, we all know that the diligent practice is the vital and only way to learning English well. Additionally, teachers can not only organize the various and colorful activities in the classes in a rather free learning plan, but also create the atmosphere of group learning well. "Requirements for College English Curriculum" made the following demands for the teaching mode focusing on the characteristics of traditional teaching mode: Diversify the teaching modes; informationize the teaching methods; autonomization and personalization are necessary for students learning; create a new pattern which is teacher-guide and student-center; inherit the excellent part from the traditional teaching mode. Thus, we can see the adopting of multimedia teaching mode does not aim to abandon all the contents of traditional teaching mode but to integrate for reaching an optimum result in teaching.

\section{B. Multimedia Teaching Mode}

Multimedia teaching refers to the special teaching procedure which applies the multimedia and computer to the process and need aids from multimedia software made previously to carry out teaching activities in the class, also named after CAI, computer assisted instruction. Multimedia computer widens the teaching space instructed by computers, enriches the resource of college English teaching, stimulates the activity and initiative of students and bring us good learning consequences with its vivid expressing manner and abundant language environment. "Requirements for College English Curriculum"pointed out: "every university should explore and built up listening-speaking teaching mode under the network environment based on the self conditions and the English level of students; do the teaching and training practice on line directly, whether on local area line or school line. Extensive reading and literacy translation teaching can perform in both the common classroom and the internet environmental classroom." The vital feature of the multimedia technology is characterized by the rich resource in teaching and the diversity of vision, multimedia can combine the words and images with the sound to show the result in three dimensions on the screen. Multimedia courseware is complex in species, integrate in fusing the graphic and audio-visual, easy to operate and large in performing. When students do the college English practice with multimedia courseware in learning, they could immerse themselves into a free studying space vividly which is mixing sound transmission, text understanding and video displaying, so the sensory stimulation will promote to improve a better learning outcome. Additionally, multimedia has an incomparable nature in imitating language environment. The integration of desired sound, vivid images, flash animation in the process of producing the courseware production can approach the reality on a large scale, which could bring an immersive feeling to the students. The sharing of network resources makes possible for students to study with multimedia computer because it expands the time and geographically endlessly and break out the barrier made by time and distance. Interactivity of resource application stimulates students' activity, initiative and innovation constantly, so it satisfies the students with curiosity for knowledge and extends the students'sensible space and exploration field. All in all, the merits of multimedia computer concern on the abundance of information, the rich materials and the diverse forms, which would offer us the possibility of autonomous studying and would serve a good way relatively for exploring their own proper learning method comparing with the static method teachers performed.

Compared with the traditional teaching mode, the multimedia computer has unparalleled advantages, but it also has its limitations as following: first, multimedia teaching ignored the teachers as a guide in the class, multimedia courseware became the core of learning and led the students' learning dynamics. Under this situation, the students lack the necessary emotional communication in the class, and the class changed into the single knowledge flow from machine to people. Second, ignoring the role of teachers is to exaggerate the students' initiative in the class actually, which makes college English learning turn into the experimental class cut down the interest of students. Third, when the teachers control the mouse only, just demonstrate the courseware content in the class, they just change their identity from teacher into a computer operator, or even a dispensable participant, it is ridiculous; and it is hard for students to stir the imagination because the multimedia courseware, teaching procedure and learning contents were all pre-designed by teachers. If the network class becomes a simple mechanical operation and a tedious man-machine talking, the students only have a scanty understanding when the class finishes. The results deviate from the application of high technology in our plan. We can summarize easily that the advantages of multimedia computer technology are imitating a realistic language environment with the mixed stimulating from the use of auditory, visual and other sensory, but we cannot avoid the negative influences such as the learning effects should give way to the learning feeling, the contains of learning would be weakened, the attention to knowledge would be distracted. We must admit that multimedia technology is only aided teaching tool in presentation. If students put too much attention on the simple presentation of new things and the displaying of knowledge, if students put too much absorbance into the obvious color, pictures and animations, if students are only attracted by those comprehensive stimulus, they would waste their attention on the presentation and be misled by the displaying of kinds of multimedia skills and techniques, so the ignoring of learning contains is not inevitable. 


\section{RESULTS AND ANALYSIS}

Exploration on multimedia teaching mode in CUST----reading comprehension teaching as example

In Changchun University of Science and Technology, the English teachers tried to immerse multimedia computer teaching mode into college English reading in order to improve the reading skills and level of students under the new situation and to deal with the problems brought by large-class teaching, and build up an integral and reasonable assessment system simultaneously for inspiring the studying interest buried in the deep soul of students, then the widening the horizon is the subsequence result maybe. So we took the multimedia computer teaching mode as a sample from two aspects as following:

Grading teaching in our university has been implemented for many years, "rule of three levels" is the usual way in teaching. The rule of three levels refers to a dividing measure based on the marks students were graded in a test, three levels together, a level represents the students who have the high marks, $\mathrm{C}$ level represents the students who have the low marks, the rest parts belong to $\mathrm{C}$ level. Accordingly, B level has a large portion in the three, sixty percentage nearly. The two extremes occupy twenty percentages respectively. We combine the grading teaching with multimedia teaching mode, the grading teaching could satisfy the individual need in a large scale and the multimedia teaching mode could reach the individualized teaching actually. So how to improve the teaching effect in the large-class of grading teaching under multimedia teaching mode is the point and the problem need to be resolved.

One is the combining of teaching in large-class and counseling in small-group. Our university finished building up many multimedia computer classrooms in east campus and west campus by the end of 2010, and the teaching in large-class and counseling in small-group mode is gradual ripen. As to the extensive reading lessons, the multimedia teaching CD-ROM matching with the English text books are adopted in our school, and we take the large-class teaching with computer screen (undoubtedly, there are still many teachers standing in front of blackboard for imputing language to students ). And for some lessons that need communicating among teacher and students, for example, oral English, discussion class and audio-visual lessons, are took the small-group learning.

The other is the combining of classroom teaching and self-learning. Teachers are in charge of organizing the classroom teaching. During the face to face communication of teachers and students, the duty of teacher is to create a flexible teaching plan, to highlight the reading methods and learning skills under the guidance of the syllabus focusing on the reading needs of students. Teacher also should help and monitor students with their task by explaining, supervising and checking. The self-learning method featured by non-regular and multi-form could help students stretch their weekly English classroom learning time into non-regular, multi-directions learning space to accommodate students who are in different levels in different way with different reading demands and aims to show the personalized teaching principle.

In the half year empirical study around one hundred ninety three freshmen who are in B levels in our university by investing the situation under the multimedia computer teaching mode with questionnaire. The finding is that one hundred seventy six students prefer to the multimedia teaching mode than the traditional mode. New reading mode is circling around the multimedia teaching, which require the students to be accustomed of self-learning. The consequence confirmed that this requirement did not trouble the experimenters, on the contrary, improved them to perform the effective learning plan designed carefully beforehand and arranged the studying time by them. We got a satisfied result that the experimenter agreed in getting aid from this teaching mode. And one hundred fifty one students were sure of enhancing on the reading skills and reading range. Reading ability was strengthened in the process. Integrate learning ability was improved as well as the understanding about the western culture and language history was enriched in the learning procedure.

But nothing could reach the acme of perfection at once. The multimedia teaching mode brought some problems to the teachers and students in the experimental period yet. Network multimedia teaching mode should be constrained by network and computers. Self-learning ability is a weak part for students who suffered exam-oriented education so many years. Small-group counseling class and small internetwork audiovisual class overlook the role of teachers. The current evaluation system conflicted with the teaching strategy. In addition to the previous points, the financial problem occurred with researching online for information is a burden for some students. So we should continue researching on the project and point out some key to our teaching mode.

\section{DisCUSSIONS AND CONCLUSIONS}

Integration of traditional teaching mode and multimedia teaching mode

Based on analysis, multimedia computer teaching has superior advantages as a new type teaching mode accordingly, simultaneously some shortcomings are unavoidably. As to the traditional teaching mode, although there are many undesirable aspects, it is not good for nothing at all. In the reforming of teaching mode process, we must apply the reasonable sections to the teaching practice appropriately. Traditional mode and multimedia mode are not completely opposed to each other; a great complementary exists between them. We should combine them into integrity in order to cultivate the talented students who hold steady essential language skills and have the ability to communicate with language frequently.

Firstly, the emotional communication of traditional teaching mode should be immersed into multimedia computer 
teaching mode. Teachers should demonstrate the teaching activity with the courseware flexibly in the class; they should dig out the emotional content of curriculum effectively at the same time. Teachers could be sensible to strengthen the emotional communication at right timing, enhance the emotional joint between teachers and students, and change the method and contains with the changing of class atmosphere. Thus students can not only play their initiative role but also absorb the knowledge effectively. Secondly, the tasks that students must fulfill during the multimedia teaching process should be refined. Cultivating the self-learning ability is the key to new multimedia computer teaching mode though, the students who were taught by knowledge-filled teaching mode for many years cannot reach for the self-management level at all, and they are not habitual of doing decision-making by themselves as soon as they go to the college. They rely on the guidance from teachers usually; they are good at obeying and being controlled so they dare not to study on major subjects freely and initiatively. So teachers must design the task delicately with a planned, phrased method to distribute step by step according to the actual needs of teaching. In this process, students always are in the active state of learning knowledge and exploring the unknown world before they complete the missions. In details, the tasks can be divided into "previewing assignment" "class target" "reviewing homework", teachers should support different requirement and learning progress focusing on different students generally according to kinds of tasks and different English level, which could be called as individualized learning. So the students could realize the personality and initiative by accomplishing their own studying target under guidance of teachers. Thirdly, the assessment measures should be perfected in the multimedia computer teaching mode. Teaching assessment plays an important role in teaching management, judging the progress and quality of students, ensuring the teaching quality and so on. What's more, the fairness of the assessment and the results of evaluation could influence students in many ways, even including the forming and reforming of their worldview and values. The duality of teaching assessment in teaching mode reforming could not be ignored. In addition to the midterm and final examinations that value the proficiency of students, it is necessary to have routine assessment for learning. Moreover, the assessment between students, the assessment between teachers and students, and the self-assessment are all vital too. In order to improve students to study hard and effectively, we can use many ways in the flexible teaching mode, for example, recording classroom activities and the extracurricular activities, interviewing, and discussing, forming the study recorder, evaluating and supervising the learning process etc. Last, the requirements for the teachers are the essential factors for performing the multimedia teaching mode smoothly. Teachers should hold a profound knowledge and professional theory level; teachers should enjoy the greater hardships in preparing the teaching information assembling and in classifying the teaching materials. Teachers should grasp the developed multimedia application techniques, and they should have higher ability to control the classes and experienced skills to explain the extensive English knowledge. Only in this way can the teachers enlighten and inspire the students with colorful artistic teaching methods and superb lectures by the advanced multimedia teaching facilities. Thus the learning motivation could be improved to get the consequence that college English teaching level and learning efficiency could be enhanced ultimately. Multimedia is not the reducer for English teaching, but the engine. It would not only lead the teaching speed of teachers, but also promote the English learning pace of students.

"Requirements for College English Curriculum"(revised edition) published by Ministry of Education points out that "all universities should make use of modern information technology entirely and take new teaching mode based on computer media teaching and traditional class teaching for reforming the single teaching mode based on teacher-center teaching mode. The new teaching mode should serve students the free space not to be limited by time and place with the support of modern information technology, so as to developing to personality and initiative." We all know that personality and initiative are the educational goal for the public, "education should aims at mastering how to learn, and when mastering, students could learn by themselves, then they could absorb the new knowledge, new techniques positively and accept the new challenge, new task bravely."(Wen Qiufang,2002, P.11 ) The multimedia teaching mode based on studying themselves are worthy of encouraging, but the traditional guidance of teachers in the learning process is not be ignored easily. Multimedia is a tool only, whether it could get a better effect or not is still a problem in teaching, the result depends on how teachers apply it to the teaching process. Appropriate arrangement could expand and stretch the class; conversely, it would affect the effectiveness of teaching. Teachers need to deal with the language input and output relationship for the learners in the teaching process when organizing the class activities, as well as they need to combine the traditional teaching method and multimedia teaching mode together in order to promote the students to digest and absorb the knowledge they learned and turned the knowledge into practicing after they finish guiding and explaining the knowledge to students in the class.

\section{REFERENCES}

[1] Chua Gang. (2001) New modes exploration in College English Intensive Reading. Foreign Language http://epub.cnki.net/kns/brief/default_result.aspx (accessed 25/10/2001).

[2] Cao Hong, Wu Jingru, Zhang Yang. (2004) The use of network teaching in traditional teaching. Shanxi Medical University: Preclinical Medical Education Edition, http://epub.cnki.net/kns/brief/default_result.aspx （accessed26/08/2004).

[3] Cui Ling. (2005). New ideas, new systems, new modes, new methods of College English teaching -- Comment on "New Concept English (New Edition) Network Teaching System" foreign language http://epub.cnki.net/kns/brief/default_result.aspx (accessed05/02/2005).

[4] Ding Gang, Liu Lei. (2003). Constructivism and network-based Foreign Language Teaching. Foreign Language Education 
http://epub.cnki.net/kns/brief/default_result.aspx （accessed20/10/2003).

[5] Feng Juehua, Cui Huipu. (2006). The Experimental Analysis on Multimedia Assisted College English Teaching, Foreign Language Education http://epub.cnki.net/kns/brief/default_result.aspx (accessed20/04/2006).

[6] Feng Qi, Wan Hua. (2003). Experimental report on College English Multimedia Teaching, foreign language http://epub.cnki.net/kns/brief/default_result.aspx (accessed25/08/2003)

[7] Li Yintao. (2003). Multimedia Projector Classroom Teaching. Foreign language http://epub.cnki.net/kns/brief/default_result.aspx (accessed 25/06/2001).

[8] Liu Runqing. (1999). Reform of College English Teaching. Beijing, Foreign Language Teaching and Research Press.

[9] Liu Runqing, Dai Mancun. (2003). Research on Innovation and Development Strategy of Chinese Foreign Language Teaching. Beijing, Foreign Language Teaching and Research Press.

[10] Long Yu. (2005). Problems and Solutions of Multimedia Teaching. Teaching and Management. http://epub.cnki.net/kns/brief/default_result.aspx (accessed 27/05/2005).

[11] Lu Liangqiu. (2003). How to optimize the College English Teaching. North China Electric Power University (Social Sciences) http://epub.cnki.net/kns/brief/default_result.aspx (accessed 20/01/2003).

[12] Requirements on College English Curriculum of Higher Education. (2007). Shanghai, Shanghai Foreign Language Education Press.

[13] Chen Yanqiong, Liu Li. (2007). Complementary strengths in Multimedia Teaching and of traditional classroom teaching. Education and Career, NO.11. http://epub.cnki.net/kns/brief/default_result.aspx (accessed 11/04/2007)

[14] Su Dingfang. (2000). Reform on language teaching: Problems and Countermeasures. Shanghai, Shanghai Foreign Language Education Press.

[15] Wen Qiufang. (2002). Revision for Strategies in Learning and Using Second Language (by Cohen A. 2002). Beijing, Foreign Language Teaching and Research Press.

[16] Wu Shujing. (2003). College English Teaching: Problems and Solutions. Foreign Language Teaching and Research http://epub.cnki.net/kns/brief/default_result.aspx (accessed 20/05/2003).

[17] Wu Yingjie. (2006). Discussion on College English Teaching Based on Computer Network Mode. Modern Education Sciencehttp://epub.cnki.net/kns/brief/default_result.aspx (accessed 20/01/2006).

[18] Zhou Binglan, Xu Lin, Li LvJiong. (2006). Reform on College English Teaching. Education and Modernization http://epub.cnki.net/kns/brief/default_result.aspx (accessed 30/06/2006).

Kun Liu was born in Tonghua, Jilin Province, China in 1979. She received her Master Degree in Foreign Linguistics and Applied Linguistics from North East Normal University, China, in 2007.

She is currently a lecturer in the Foreign Language College, Changchun University of Science and Technology, Changchun, China. Her research interests include linguistics and intercultural communication. 